\title{
Building Effective Outcomes within the Community - Case Study in the Field of Disabilities
}

\author{
Palani Thevar ${ }^{1,3, *}$, Venkat Pulla ${ }^{2}$ \\ ${ }^{1}$ Australian Catholic University, Australia \\ ${ }^{2}$ Social work discipline, Australian Catholic University, Brisbane, Australia \\ ${ }^{3}$ Queensland State Government, Australia \\ *Corresponding Author: palanithevar@gmail.com
}

\begin{abstract}
In the field of community development there are a number of funding models. Communities that have identified their common needs and are working towards ameliorating may seek resources within (self-funded), raise resources outside their community (donation seeking), or depend on and utilise government funding (state funded). The 'South West Brisbane Disability Network' (SWBDN) has been established as an unregistered network of service and provides a broad field of disabilities, to address community interest and advocacy options to improve quality of service provision. This paper presents the common objectives for which the Network was created and the process through which a number of successful outcomes were negotiated.
\end{abstract}

Keywords Community Organisation, Stakeholder's Development, Disability

\section{Introduction}

In the field of community development, there are a number of funding models. These include funding from the government, fund raising charity in communities or self-resourcing. Others may raise resources outside their community through collecting donations. In disability services there are two different types of service providers. The government sector is responsible for providing legislation, practice standards, information, support, guidelines, and funding. It is directly or indirectly responsible of overseeing services in the community sector. The second is non-government organisations (NGO) who are largely responsible for providing services within the community. The trend is increasingly driven by value for money and user pay imperatives. In Queensland the government is "driving reforms that deliver value for money and manage public investment well" (Queensland Department of Communities, Child Safety and Disability Services, 2014) in the service delivery system. That means that an NGO needs to be accountable and be cost effective and competitive in terms of service delivery. There is an imperative to work together, providing co-ordinated service delivery and sharing what we have to help each other. Most NGO service delivery is based on government funding. Unfunded models are not considered to be as effective. Through practical experience and understanding of assessed need, the first author, as facilitator, identified service gaps in the area of disability. This helped a working group to consider some models to bring service providers in the field of disability, mental health and other related services in the community for a meeting. As a result it was decided to establish a Disability Network for South West Brisbane, Australia in 2009.

\section{What is the Disability Network?}

The South West Brisbane Disability Network (SWBDN) is a platform for bringing service providers together regularly to learn and help each other in service delivery. After many discussions with senior professionals and doing some research over a period of time, it was identified that there is a need for disability specific inter-agency reference and support group. But there was no particular will to bring service providers together for disability specific inter agency meetings or disability specific networking agency meetings in the area of south west Brisbane. There were many general community inter agency meetings being organised by various community organisations including mental health, but there was also strong support to do something for the disability sector specifically. This provided encouragement to create such a platform in the area. This opportunity enabled service providers to meet, share and network with various services that were working with people with disability, including mental health. This model has now been established and tested over five years in the community.

\section{Purpose and Reasons for South West Brisbane Disability Network}

Community needs and issues vary and the needs of service 
providers are different in their own settings. In the field of disability, government sectors are responsible for providing direct care and support to the community. Historically for several decades, services in south west Queensland had been provided in places like Ipswich and Wacol near Brisbane in big institutions that were isolated from their communities. In the field of disability, a major reform of de-institutions occurred in Queensland in the 1990s. With major reform the numbers of non-government disability service providers started to increase. They competed for the funding and expectations about quality of service provision for people with a disability became greater than before.

Healy (2012 pp 77-78) has noted that "In order to enhance service user's access to networks and services, the caseworker at a minimum requires a comprehensive understanding of existing networks and services relevant to service users and a capacity to work with the service users to identify a broader range of networks and services that may be relevant to them. However, from a radical casework perspective, it is also important that the case worker is active in maximizing the range of networks and services available to the service user".

Collective efforts can produce great outcomes; working together creates greater spirit and widens our capability to provide better service to the community. Zastrow (2006 p53) notes that "it is strategic to link people with systems that provide them with resources, services, and opportunities". The purpose of the South West Brisbane Disability Network is to provide service in the field of disability, mental health and other related fields together to share, support, and network with each other to serve the community better with their coordinated service delivery.

\section{Structure and Process SWBDN}

The disability Network meetings are conducted once every two months on the Thursday in the last week except that each year the week may vary due to public holidays; we hold six meetings per year. Attendance at these meetings varies between 15 - 50 service providers; mostly over 25 service providers attend these meetings. SWBDN sends communications to all service providers by email. In some instances meetings are announced through other general interagency meetings, by flyer invitation and so on. Meetings schedule, time and often venues are finalised in advance at the end of each year for the following year. The venues are rotated to provide everyone an opportunity to know and learn about various services in the community.

The meetings encourage people to meet and interact with their peers and learn of the existence of other agencies, services, etc. The authors were surprised to learn that for many service provider these visits have been for the first time in their professional life. Venues are provided by participating agencies and the provider becomes the host for each meetings. The cost is absorbed by the hosting agency, which provides morning tea (tea, coffee, snacks, etc.) based on their available resources.
A regular agenda for the meetings is as follows:

- Meet and greet each other, providing an opportunity for informal interaction

- Acknowledgment of traditional owners of the land.

- Reiteration of group goals and process for new comers

- General business with attendees invited to participate

Meetings run for two hours in the morning from 10am to 12noon. Everyone briefly introduces themselves and their organisation. All service providers are encouraged to bring information to share, including their contact information, organisation or service flyers and so on and later on, all get an opportunity to share and explain about their organisation, services, events, referral process, and any new information to share. In all the meetings, information is displayed on a table and participants are encouraged to provide their information for others to take with them. Participants are reminded to avoid any politics and not create disputes or air current issues during this time. Disability Network aims to creates a sense of collective, rather than individual business.

Mostly attendees are not invited to address the meeting because most participants would not have an opportunity to speak and the quality of networking prospects might be compromised. However, in few occasions maximum of 10 to 15 minutes time is set aside for participants to provide presentations on very important matters. In this case everyone gets an opportunity to speak for a maximum of 2 to 3 minutes based on the number of participants and availability of time. Interaction, outside of meetings is encouraged. This includes giving presentations at each other's venues and sharing professional development. The minutes include each organisation, individual contact information and the service offering from their organisation or service. The minutes are regularly updated and shared with all participants electronically. However, a few hard copies are provided at each meeting for participants to check and amend if any updates are required.

\section{Successful Story and Feedback of Disability Network}

Hospitality is a key for success and organisations often voluntarily come forward to provide their venue and morning tea etc. Prior to starting this network, there were large numbers of service providers not known to each other. The network has increased the level of interaction and brought people together to provide better services for the people they work with in the community. Attending these disability specific network meeting has increased healthy competition with a positive outlook. All participants share information with others, invite others and leave information for new workers or organisations to follow up when they finish meetings. It is so encouraging to see and hear email or phone from many attendees to let us know when they resign or leave the organisations for various reasons. This 
strengthens the work we do to support, invite and bring them together for helping the community we work with. Disability network agencies do work closely with other government and non-government health and human services organisations to support our clients to increase the service provision. This has enabled and provides energy to continue to journey together with. Everyone has lots of work to do and some instances do not have time to carry anything other than their routine. Everyone's knowledge and awareness has increased about the number of service providers providing a variety of creative work in the disability sector. Interpersonal communication and helping each other has increased though the number of referrals process. Finding a host and a venue has been a difficulty on only few occasions for over the last five years.

This network is known not only in Brisbane but also in other parts of Australia. Services from South Australia and Victoria have contacted the first author seeking and sharing important service information. There is always someone to contact and wanting to know when there is a next disability network meeting. Often people want to be invited or added to the invitee list for future meetings.

\section{Feedback on the Network}

The following is some feedback about the Network.

A professional trainer who provides training for parents and workers to work and manage well in the field of disability indicated:

'The South West Brisbane Disability Network Meeting is a valuable way of networking with like-minded people who are interested in supporting individuals and families dealing with disabilities. As a small business, she would like to keep up-to-date with information and services that she can pass onto parent and carer clients who attend my workshops. She feels it is important for departments, organisations, agencies and service providers to work in collaboration to provide the best outcome for clients. The contact and working relationships provided through the meeting and follow up emails keep members up-to-date with current information'.

A social worker from health services provided feedback as follows:

He wants to formally give the department and facilitators some positive feedback about the South West Brisbane Disability Network. He finds the Network invaluable for his work within his Health Service. It allows him to quickly and easily reach Disability Support Organisations about his services and public health announcements relevant to people with disability. In addition to allowing his service to promote their activities and offerings, he also appreciates the updates he has received about other services, events and training opportunities and the professional contacts he has made through the Network.

In particular he has noted that he has been able to promote new disability-access enhancements at their Dental Clinic. The first author was able to forward promotional email about a Clinic Open Day for adults with disability. The event was $60 \%$ full by the end of the same day. The tour ended up being $25 \%$ overbooked and an additional 20 information packs were sent to other callers. The service providers have seen a significant increase in the number of people with disability accessing the clinic. Many of these clients had not seen a dentist for many years.

One of the disability service workers who is very much connected with the community in his capacity to provide information and support for individuals and families commented as follows: "I really appreciate this Interagency as it provides a more disability specific networking/info sharing opportunity. I can't think of any way that it could be improved."

At the same time, improvement will always enhance the quality of service provision. A senior and experienced worker from a large non-government organisation said that she has found the South West Brisbane Disability Network to be very productive to attend, as the number of service providers attending; information they provide; and referral options made available are very beneficial in support of her clients. She says that this enables her to assist my clients with a variety of options, when supporting them with future planning, as it gives her clients a wider base of service providers to choose from when assessing their current care needs, future care needs and connecting with relevant supports for their loved ones and themselves. Especially, the worker said, the way in which the Network provides specialist guest speaking opportunities also is invaluable in helping network attendees, such as herself, stay conversant with current, new and relevant services that may be of assistance to their clients. She expressed that the network is very well organised and facilitated.

These are a few examples written and provided about experiences of the Network. A very experienced psychologist working for the Health Department told in another public forum that attending SWBDN meetings was a most effective and enjoyable experience. Much information is sought and given through the Network meetings and email groups. She attended meetings and subsequently went on leave. During this time she asked her relief staff to attend these meetings and this has proved very useful for their service. Since her return to work she has attended several meetings in person. She notes that Network attendance is encouraged in staff hand over processes. It should be noted that this is a frequent occurrence across the Network.

\section{Skills and Awareness Required in Facilitating Inter-agency Meetings and Facing Challenges}

Getting the Network up and running and providing a 
consistently high quality and valuable event has presented some challenges over the years. Access issues have been a particular problem in some venues, for example. This has included locations that have not been suitable for participants, including wheelchair access. Auslan interpreters have also not proved to be consistently available.

Finding a consistently useful structure for the meetings has been, and continues to be a challenge. For a few, the repetitive structure of the meetings has proved boring, while others have found the same structure to be useful. Several people wanting to attend these meetings were unable to attend regularly due to various commitments. This has proved a mixed blessing with some welcoming the opportunity to meet new services and staffs attending these meetings.

For others, the nature of the network does not allow the discussion of practical issues during the meeting. This network is not run as a traditional inter- agency meeting: there are no regular speakers as in other network meetings, for example. A few get confused about whether the Network is within their region or catchment areas, however, they do get to know some agencies that attend and provide cover across catchment areas. Providing a map of catchment area would be useful. However, the boundary of catchment areas has been modified at least three times since the establishment of SWBDN since 2009.

\section{Work to be done in Future}

Identifying challenges and safeguards to ensure the maintaining of the Network's objectives is very important. Limitation of Network, functions and participation to the South West Brisbane area is necessary to ensure efficient meetings of the goals of the Network. In reality, if we have more than 50 participants in the meetings it will be less productive. Therefore, creation of similar networks can be supported and training provided to establish and run similar groups in other areas of Brisbane.

A guide could be produced on how to run a network on this specific field like the South West Brisbane Disability Network.

\section{Running of SWBDN}

Initially it took several months to do research, consultations to start this group five years ago. The authors must acknowledge the great help from his organisation and managers, who were able to support and encourage the implementation of the Network.

Peck \& Dickinson (2008) note that collaboration and partnership may influence the management of challenges that may be encountered in the journey of running a Network. Currently the first author has sole responsibility for maintaining and running the group effectively. Initially it was formed with five people to be as a working committee.
Over the period, people have moved on and resigned from their job. This of course has prevented them from attending and participating in planning. One person running the organisation is not viable in the long term; options of having more facilitating people would be an advantage and will be explored in the new year.

Each attending organisation that is able to host a meeting for service providers with a minimum of 25 to 50 people also provides basic catering for this event once a year. With ongoing commitment to services, providers are willing to host these meetings as they are cost effective. The SWBDN is an effective and vibrant structure provides opportunity for large part of Brisbane and surrounding areas.

\section{Conclusion}

Coordinated service delivery is an essential part of empowering a community to be an effective champion for people with a disability. The Disability specific inter agency meetings have relevance in the current disability service. This additional informal structure strengthens disability services and provides local support as Queensland transitions to the National Disability Insurance Scheme (NDIS). This model of networking can be usefully duplicated in other regions or other parts of Australia or elsewhere. The existence of the Network has brought in previously isolated services and individuals into contact leading to participation in each other's professional development events, research projects, knowledge, sharing of physical resources and training resources, funding sources, etc.

\section{Acknowledgements}

The authors would like to acknowledge the following who have supported and provided their input: Chris Montgomery, Lynne Monahan, Simon Leis, Reg Stuart and key people from Disability Services, Department of Communities, Queensland Government and the Inala writers group.

\section{REFERENCES}

Disability Services (2014). Annual Report 2013-14. [ONLINE] Available at:

http://www.communities.qld.gov.au/gateway/about-us/corporate-p ublications/annual-report/annual-report-2013-14. [Last Accessed 11 Nov 2014].

Healy, K., (2012). Social Work Methods and Skills: The Essential Foundations of Practice. 1st ed. Hampshire: Palgrave Macmillan.

Oliver, M. (2009). Understanding disability. $2^{\text {nd }}$ ed. New York: St. Martin's Press.

Osburn, J (2014). Overview of Social Role Valorization Theory. 
[ONLINE] Available at:

http://www.socialrolevalorization.com/articles/overview-of-srv-th eory.html. [Last Accessed 11 Nov 2014].

Peck, E., and Dickinson, H., (2008). Managing and leading in inter-agency settings. Bristol: Policy Press in association with Communitycare.

United Nations Enable (2014). Convention on the Rights of Persons with Disabilities. [ONLINE] Available at: http://www.un.org/disabilities/convention/conventionfull.shtml.
[Last Accessed 11 Nov 2014].

Pulla, V., Chenoweth, L., Francis, A., and Bakaj, S, (2012). Papers in Strengths Based Practice. 1st ed. New Delhi: Allied Publishers Pvt. Ltd.

Wolfensberger, W., (2012). Social Role Valorization : Advanced Issues in Social Role Valoriszation Theory. 1st ed. Plantagenet: Valor Press, Ontario.

Zastrow, C. (2006). Social Work with Groups: A Comprehensive Workbook. $6^{\text {th }}$ ed. Belmont, CA: Thomson/Brooks/Cole. 